\title{
TOWARDS MINING THE MINE WATER - RECOVERY OF ALUMINIUM AND MANGANESE
}

Laurentiu Razvan Dinu ${ }^{1}$, Ioan Balaiu ${ }^{2}$, Ionut Cristea ${ }^{1}$, Viorel Ion Patroescu ${ }^{1}$, Cristiana Cosma ${ }^{1}$, Lucian Alexandru Constantin ${ }^{1}$, Valeriu R. Badescu ${ }^{1}$, Mihaela Alexie ${ }^{1}$

${ }^{1}$ National Research and Development Institute for Industrial Ecology ECOIND, Str. Drumul Podu Dambovitei 71-73, 060652, Bucharest, Romania, email tehnologi@incdecoind.ro

${ }^{2}$ Mining Research and Design Institute SC ICPM SA Str. Grivitei Nr. 89, 430323, Baia Mare Romania, email icpmbaiamare@yahoo.com

\begin{abstract}
Mine water or rock drainage is a source of pollution for Romanian as well as for mining sites all around the world. Rock drainage is generated as a result of the weathering of the sulphidic minerals from which metal ions are leached. The metal ions are the main polluting species existing in the mine water, but may also be seen as a resource that is wasted. However, the recovery is seldom applied, as it is not feasible due to complex chemical matrix. Some types of mine water are more appropriate for the resource recovery, the best known case being copper reach streams. Here we show some attractive results suggesting that the recovery of aluminium, but also of manganese would be feasible practices for particular mine water categories and for distinct utilizations: mine water treatment and high purity resource for metallurgy, respectively.
\end{abstract}

Keywords: aluminium, manganese, mine water, recovery

\section{Introduction}

Mine water from abandoned mines has a harmful impact on the ecological status of receiving water bodies. The metal ions in the mine water are the main deleterious species, but may represent a recoverable resource.

Beside the availability of (still) cheap ore resources, mine waters vary considerably in the range and concentration of heavy metals they contain and these issues can lead to the failure of the recovery of potentially valuable metals.

Studies are focussed mainly on the recovery of $\mathrm{Fe}, \mathrm{Cu}$. $\mathrm{Zn}$ and Ni, generally using the techniques of selective precipitation, precipitation and dissolution, solvent extraction, electrowinning and ion exchange.

Iron is the most abundant metal in mine drainage and various recovery options were tested, such as the direct use of the ochre deposits as brick component [1], as pigment ${ }^{[2]}$ or as reactive substrate for trace elements and nutrient removal ${ }^{[3],[4]}$, or the conversion of ochre and mine water treatment sludges by acid dissolution for use as coagulants ${ }^{[5]}$.

The options for copper recovery include direct electrowinning, using copper reduction on iron metal and copper precipitation using biogenic produced hydrogen sulphide such as in the Paques or BioteQ systems ${ }^{[6]}$ (technique that works well for $\mathrm{Zn}^{2+}$ also).

Aluminium may be present in mine water in concentration from near zero to more than $4 \mathrm{~g} / \mathrm{L}\left[{ }^{8]}\right.$, but researchers rarely show interest for the recovery of this element, because of the high cost needed to use the impure recovered product for metallurgy. However, alternatives for aluminium valorisation were observed. For example, a poly-alumino-iron sulphate coagulant useful for the 
removal of suspended solids and colour can be produced by precipitation of $\mathrm{Fe}^{3+}$ and $\mathrm{Al}^{3+}$ followed by dissolution in sulphuric acid ${ }^{[9]}$.

On another hand, the aluminium recovery and reuse for advanced treatment of mine water via sulphate removal as ettringite is possible and it was studied and presented in a previous paper

[10]. The recovered aluminium in hydroxilated form can be used without intricate purifying steps, for the further processing of the source mine water, or transferred to other mine water site, mainly when the aluminium quantity is exceeding the water source requirements treatment requirements. This case will occur conditioned by the specific discharge limits and the amount of aluminium in the mine water. Such a case is presented here, for a highly polluted AMD.

Due to the relative low cost of manganese ore and due to the frequent association in the mine water with metal species which precipitate to a high $\mathrm{pH}$, which complicates the selective separation process, manganese recovery from mine water is generally not referred as an interesting issue.

In this paper we show a case study showing that the recovery of manganese may be feasible from certain mine water sources.

\section{Experimental}

\section{Aluminium Recovery}

Mine water from a certain source from Romania, named "PR", having a very high content of heavy metals, aluminium and sulphate (Table 3) was treated in the first step with magnesium hydroxide with mechanical stirring to $\mathrm{pH}=5.2$ for 20 minutes and the precipitate was separated by centrifugation (1650 x g, 5 minutes). The precipitate (Sludge I), was tested in the next step as an aluminium source for sulphate ion precipitation as calcium sulphoaluminate (ettringite).

A mine water effluent produced by conventional treatment by liming, having $\mathrm{c}\left(\mathrm{SO}_{4}{ }^{2-}\right)=2036 \mathrm{mg} / \mathrm{L}, \mathrm{c}\left(\mathrm{Ca}^{2+}\right)=802 \mathrm{mg} / \mathrm{L}$ and TDS $=2976 \mathrm{mg} / \mathrm{L}$ was contacted with S/udge I (aluminium dose $400 \mathrm{mg} \mathrm{Al} / \mathrm{g} \mathrm{SO}_{4}{ }^{2-}$ ), for 50 minutes. Calcium hydroxide was added to establish and maintain the $\mathrm{pH}$ to the value of $11.6 \pm 1$. The effluent was analyzed after settling and filtration for sulphate, calcium, magnesium and TDS.

\begin{tabular}{|c|c|c|c|c|c|c|}
\hline Parameter & $\mathrm{pH}$ & EC & $\mathrm{Al}$ & $\mathbf{F e}$ & Mn & $\mathrm{Zn}$ \\
\hline Values & 2.33 & 15.1 & 3690 & 2947 & 49.1 & 108 \\
\hline Parameter & $\mathrm{Ca}^{2+}$ & $\mathrm{Mg}^{2+}$ & $\mathrm{SO}_{4}{ }^{2-}$ & TDS & & \\
\hline Values & 401 & 720 & 29360 & 48560 & & \\
\hline
\end{tabular}

\section{Manganese recovery}

Mine water from lacobeni mining perimeter (Romania), having elevated manganese content and low concentrations of iron and other heavy metals (Table 4), was identified as a promising source for manganese recovery. The mine water quality was monitored for medium term interval, 20082015 (Table 5, Figure 12).

Manganese was recovered using a two step process operated in batch mode. In the first step, iron was separated by oxidation and precipitation using air sparging and mechanical stirring, without addition of alkaline reagent, followed by solids separation by settling. The supernatant was treated with sodium hydroxide in order to adjust and keep the $\mathrm{pH}$ value of 9.5 and 10.5 for up to 60 minutes reaction time $(\tau)$, with air sparging and stirring for manganese precipitation. 
Water analyses for metal species were performed by AAS and ICP-MS and the filtered sludge samples was analyzed by XRF after drying and calcination.

\begin{tabular}{|c|c|c|c|c|c|c|c|}
\hline Parameter & $\mathrm{pH}$ & EC & $\overline{A l}$ & $\mathrm{Cr}$ & $\mathrm{Cu}$ & $\mathrm{Fe}(\mathrm{t})$ & Fe $(d)$ \\
\hline Values & 6.5 & 1.45 & $<0.05$ & 0.015 & 0.001 & 39 & 7.5 \\
\hline Parameter & Mn $(\mathrm{t})$ & $\operatorname{Mn}(d)$ & $\mathbf{Z n}$ & $\mathrm{SO}_{4}^{2-}$ & $\mathrm{Ca}^{2+}$ & $\mathrm{Mg}^{2+}$ & TDS \\
\hline Values & 138 & 135 & 0.62 & 859 & 128 & 69 & 1320 \\
\hline
\end{tabular}

\begin{tabular}{|l|c|c|c|c|c|c|}
\hline \multicolumn{7}{|l|}{ Table 5 lacobeni mine water - main parameter time variation } \\
\hline Parameter & $\mathbf{p H}$ & $\mathbf{E C}$ & $\mathbf{M n}(\mathrm{d})$ & $\mathbf{F e}(\mathrm{t})$ & $\mathbf{F e}(\mathrm{d})$ & $\mathbf{Z n}(\mathrm{d})$ \\
\hline Values & $6.2-6.5$ & $1.33-1.63$ & $85-135$ & $8.3-39$ & $7.5-12.5$ & $0.49-1.02$ \\
\hline Parameter & $\mathbf{C a}^{2+}$ & $\mathbf{M g}^{2+}$ & $\mathbf{S O}_{4}{ }^{2-}$ & TDS & & \\
\hline Values & $121-169$ & $27-69$ & $859-1421$ & $1320-2044$ & & \\
\hline
\end{tabular}

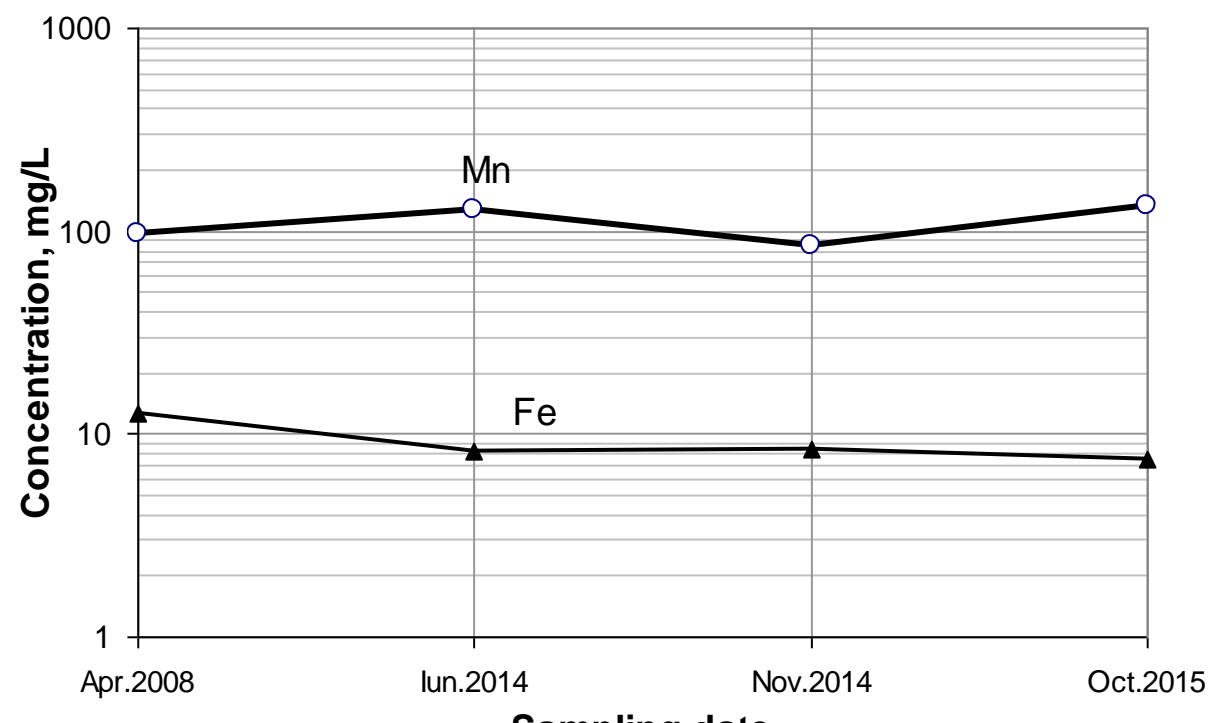

Sampling date

Figure 12 - lacobeni mine water- time variation for $\mathrm{Mn}$ and Fe

\section{Results and Discussion}

\section{Aluminium recovery}

Aluminium concentration for the " $R P$ " discharge was between $3.7 \mathrm{~g} / \mathrm{L}$ and $4.0 \mathrm{~g} / \mathrm{L}$ during observation time interval (2009-2015).

For the aluminium recovery test, the filtrated precipitate (Sludge I), with $25.7 \%$ d.w., had an aluminium content of $164 \mathrm{~g} / \mathrm{kg} \mathrm{d.w.,} \mathrm{but} \mathrm{also} \mathrm{iron,} 134 \mathrm{~g} / \mathrm{kg} \mathrm{d.w.} \mathrm{In} \mathrm{the} \mathrm{first} \mathrm{step} \mathrm{aluminium}$ precipitate as aluminium hydroxide and aluminium hydroxisulphates and the residual dissolved aluminium concentration was found to be $2.5 \mathrm{mg} / \mathrm{L}$.

After the second step, for a Sludge I dosage equivalent to $400 \mathrm{mg} \mathrm{Al} / \mathrm{g} \mathrm{SO}_{4}{ }^{2-}$, the treated water had a sulphate concentration of $342 \mathrm{mg} / \mathrm{L}$ due to ettringite precipitation. In this case, the 
aluminium utilization is $480 \mathrm{mg}$ for $1 \mathrm{~g}$ of sulphate removed, but lower values can be expected for lower conversion values ${ }^{[10]}$, corresponding for effluent sulphate concentration closer to the discharge limit of $600 \mathrm{mg} / \mathrm{L}$.

Considering the material balance, the quantity of Sludge $I$, resulted after semi-selective precipitation of aluminium from 1 litre of "PR" mine water, is enough to remove sulphate from a volume of pre-treated mine water of $2.2 \mathrm{~L}$. It is known that, by conventional liming or by conventional liming plus gypsum crystallization processes, the sulphate ion concentration can be lowered down

$1500-2000 \mathrm{mg} / \mathrm{L}{ }^{[10]}$. The aluminium quantity exceeds in this case the requirements for the treatment of the source mine water and can be transferred to other sites.

The alternative to magnesium hydroxide for the first reaction stage is calcium hydroxide [13]. Magnesium (6.7 $\mathrm{g} / \mathrm{L}$ after first step, in this case) precipitate during the second reaction step, due to high $\mathrm{pH}$, but an equivalent quantity of calcium hydroxide is required. On another hand, for a mine water with high initial acidity and high Al and Fe sulphate content, the use of calcium hydroxide will produce gypsum, so the Sludge I will have elevated sulphate content, which will be detrimental for the dissolved sulphate removal efficiency in the ettringite precipitation step.

It is obviously that refinements of the method are possible, e.g. by first precipitating the $\mathrm{Fe}$ (III) with calcium hydroxide at $\mathrm{pH} \leq 3.5$, followed by aluminium precipitation at $\mathrm{pH}=5.0-5.3$.

\section{Manganese Recovery}

As well as for other metal recovery (principally copper and zinc), the ideal feed for manganese recovery is from drainage with low iron content, but not necessary acid. Reasonably consistent feed flows and quasi-constant composition are also required to make the recovery of this metal economically attractive.

In the case of the lacobeni mine water, the manganese to iron ratio is atypically high (about 18:1 $\mathrm{mg} / \mathrm{mg}$, dissolved) is quasi-constant for a medium term observation interval of 8 years.

Iron easily precipitate by oxidation at $\mathrm{pH}$ values higher than 6.0 during air sparging step. The alkalinity of the mine water is sufficient to hydrolyze the $\mathrm{Fe}^{3+}$ ion to ferric hydroxide without a $\mathrm{pH}$ drop. Actually, by air sparging in the first step, the $\mathrm{pH}$ is increasing to above 7.5 , probably due to carbon dioxide stripping.

Manganese can precipitate from mine water as $\mathrm{Mn}(\mathrm{OH})_{2}, \mathrm{MnCO}_{3}$ or, with oxidation ${ }^{[11]}$, as $\mathrm{MnOOH}, \mathrm{Mn}_{3} \mathrm{O}_{4}$ and $\mathrm{MnO}_{2}$ (equations 1-3):

$$
\begin{aligned}
& 4 \mathrm{Mn}^{2+}(\mathrm{aq})+\mathrm{O}_{2}(\mathrm{aq})+6 \mathrm{H}_{2} \mathrm{O} \rightarrow 4 \mathrm{MnOOH}(\mathrm{s})+8 \mathrm{H}^{+} \\
& 6 \mathrm{Mn}^{2+}(\mathrm{aq})+\mathrm{O}_{2}(\mathrm{aq})+6 \mathrm{H}_{2} \mathrm{O} \rightarrow 2 \mathrm{Mn}_{3} \mathrm{O}_{4}(\mathrm{~s})+12 \mathrm{H}^{+} \\
& 2 \mathrm{Mn}^{2+}(\mathrm{aq})+\mathrm{O}_{2}(\mathrm{aq})+2 \mathrm{H}_{2} \mathrm{O} \rightarrow 2 \mathrm{MnO}_{2}(\mathrm{~s})+4 \mathrm{H}^{+}
\end{aligned}
$$

In order to obtain a low level of manganese, a high $\mathrm{pH}$ is needed for hydroxide precipitation, but also for higher oxidation rate with molecular oxygen. Generally a pH value of 9.5 to 10.5 is needed for the mine water treatment when low level of manganese in the effluent is desired [12],[13].

For lacobeni mine water, after first treatment step - deferization by air sparging, the residual soluble manganese concentration remain high, $124 \mathrm{mg} / \mathrm{L}$, close to the initial value. After manganese oxidation step at $\mathrm{pH}=9.5$ or 10.5 , manganese precipitation is fair complete. However, the final Mn concentration for filtered samples for $\mathrm{pH}=9.5$ is $\mathrm{c}(\mathrm{Mn})=1.5 \mathrm{mg} / \mathrm{L}(\tau=60$ $\mathrm{min})$, exceeding the discharge limit of $1 \mathrm{mg} / \mathrm{L}$, compared with $\mathrm{c}(\mathrm{Mn})=0.13 \mathrm{mg} / \mathrm{L}(\tau=30 \mathrm{~min})$ and
$\mathrm{c}(\mathrm{Mn})$
$=$
0.07
$\mathrm{mg} / \mathrm{L}$
$(T$
60
$\min )$
for 
$\mathrm{pH}=10.5$. Both operating $\mathrm{pH}$ values are suitable for the manganese recovery, but the discharge regulation is satisfied only for $\mathrm{pH}=10.5$.

Beside the high $\mathrm{Mn}$ concentration, high ratio $\mathrm{Mn}: \mathrm{Fe}$, the low concentration of other heavy metal ions can make the recovery of the manganese simple for this particular mine water discharge. Important, the low concentration of $\mathrm{Mg}^{2+}$ and $\mathrm{SO}_{4}{ }^{2-}$ allow to obtain a precipitation product to $\mathrm{pH}=$ 9.5-10.5 with a low content of magnesium hydroxide, but also gypsum for the case of choosing calcium hydroxide as the alkaline reagent required for $\mathrm{pH}$ adjustment for $\mathrm{Mn}^{2+}$ oxidation and precipitation. However, technical lime will always contain some impurities, so the sodium hydroxide was preferred for this exploratory study.

The maximum manganese content in the precipitate sludge was $507 \mathrm{~g} / \mathrm{kg} \mathrm{d}$.w., which corresponds to a theoretical $\mathrm{MnO}_{2}$ content of $839 \mathrm{~g} / \mathrm{kg}$ d.w. The sludge heavy metals content is low, $\mathrm{Fe}-0.7$ g/ $\quad \mathrm{kg} \quad$ d.w., $\quad \mathrm{Ni} \quad-1.3 \quad \mathrm{~g} / \mathrm{kg} \quad$ d.w., $\quad \mathrm{Zn} \quad-\quad 0.59 \quad \mathrm{~g} / \mathrm{kg} \quad$ d.w., $\mathrm{Pb}-0.05 \mathrm{~g} / \mathrm{kg}$ d.w. and below LOD for Cd, Cr, Hg and As, Sb, Se. Silicon is less than $11 \mathrm{~g} / \mathrm{kg} / \mathrm{d} . \mathrm{w}$ $\left(\mathrm{SiO}_{2}<2.5 \%\right)$.

For the commercial product $\mathrm{MnO}_{2}$ - industrial grade, specifications are $\mathrm{MnO}_{2} \geq 70 \%, \mathrm{Fe}-\max$ $6 \%, \mathrm{SiO}_{2}=4-18 \%$ (with a price of around $500-800 \mathrm{USD} / \mathrm{t}$ ).

\section{Conclusions}

Mine water problem it is likely to persist for a very long time and needs the implementation of techniques for sustainable treatment together and the recovery of resources. Two approaches were presented here, with applicability for aluminium rich or manganese rich mine water, respectively.

Aluminium recovery for mine water treatment may be a promising option for sulphate removal as ettringite to levels below $1500 \mathrm{mg} / \mathrm{L}$. Mine water generated on one site can be used as reactive aluminium source for the treatment of other mine discharges.

Manganese recovery can be also attractive, or at least can decrease the treatment cost for certain mine water sources.

\section{Acknowledgements}

This work was supported by a grant of the Romanian National Authority for Scientific Research Programme Nucleu PN 09-13 03 17, PN 16 - 250304.

\section{References}

[1] Dudeney, A.W.L., (1997), Removal and utilization of iron from contaminated waters, Clay Technology, 54, 8-10.

[2] Hedin, R.S., (2002), Recovery of Marketable Iron Oxide from Mine Drainage, National Meeting of the American Society of Mining and Reclamation, Lexington KY, June 9-13, 2002, 517-526.

[3] Sapsford, D., Santonastaso, M., Thorn, P., Kershaw, S., (2015), Conversion of coal mine drainage ochre to water treatment reagent: Production, characterization and application for $\mathrm{P}$ and $\mathrm{Zn}$ removal, Journal of Environmental Management 160, 7-15.

[4] Cornell, R.M., Schwertmann, U., (2003), Adsorption of lons and Molecules, The Iron Oxides: Structure, Properties, Reactions, Occurrences and Uses, 2nd edition. Wiley-VCH Verlag GmbH and Co. KGaA, Weinheim, 253-287.

[5] Rao, S.R., Gehr, R., Riendeau, M., Lu, D., Finch, J.A., (1992), Acid mine drainage as a coagulant, Minerals Engineering, 5 (9), 1011-1020.

[6] Menezes, J.C.S.S., Silva, R.A., Arce, I.S., Schneider, I.A.H., (2009), Production of a polyferric sulphate chemical coagulant by selective precipitation of iron from acidic coal mine drainage, Mine Water and the Environment, 28 (4), 311-314. 
[7] Weijma, J., Copini, C.F.M., Buisman, C.J.N., Schultz, C.E., Biological recovery of metals, sulfur and water in the mining and metallurgical industry, Afvalwaterwetenschap (2002) - ISSN 1568-3788, London, UK : IWA Publishing - ISBN 1843390051 - p. 605 - 622

[8] Moncur, M.C., Ptacek, C.J., Blowes D.W., Jambor, J.L., (2005), Release, transport and attenuation of metals from an old tailings impoundment, Applied Geochemistry, 20, 639-659.

[9] Menezes, J.C.S.S., Silva, R.A., Arce, I.S., Schneider, I.A.H., (2010), Production of a polyalumino-iron sulphate coagulant by chemical precipitation of a coal mining acid drainage, Minerals Engineering 23 (3), 249-251.

[10] Dinu, L.R., Stefanescu, M., Patroescu, V., Cosma, C., Cristea, I., Badescu, V., Alexie, M., (2016), Trials For The Improvement Of The Ettringite Process For The Mine Water Treatment, Journal of Environmental Protection and Ecology 17 (1), 83-93.

[11] Kurtz, S., Bilek, F., Schlenstedt, J., Kochan, H.J., (2009) Treating Mine Water Contaminated With Iron, Manganese And High Solid Carbon Loads Under Tropical Conditions, 8th International Conference on Acid Rock Drainage (ICARD) and Securing the Future: Mining, Metals \& the Environment in a Sustainable Society, Vol. 2, Skelleftea, Sweden, 23-26 June 2009, 792-801.

[12] Duarte, R.A., Ladeira, A.C., (2011), Study Of Manganese Removal From Mining Effluent, Eds.: Rüde, R. T., Freund, A. \& Wolkersdorfer, Ch., Mine Water - Managing the Challenges, Aachen, Germany, $297-301$.

[13] Aguiar, A., Xavier, G., Ladeira, A., (2010), The use of limestone, lime and MnO2 in the removal of soluble manganese from acid mine drainage, Water Pollution X, WIT Transactions on Ecology and the Environment, Vol. 135, WIT Press, 267-276. 